\title{
METÁFORA E FUTEBOL NA MÍDIA DAS GERAIS ${ }^{1}$
}

\section{Luciane Corrêa Ferreira (UFMG)}

\begin{abstract}
RESUMO: Este artigo apresenta linguagem metafórica, assim como metonímica, veiculada na mídia impressa de Minas Gerais nas reportagens sobre futebol. Analisamos metáforas e metonímias que motivam Modelos Cognitivos Idealizados a partir de diferentes domínios experienciais, utilizadas para falar sobre futebol. A análise foi centrada em dados coletados em jornais de Belo Horizonte, Minas Gerais, e utilizou como marco teórico a Teoria da Metáfora Conceitual. A pergunta que norteou essa pesquisa foi: que domínios experienciais irão mapear o domínio FUTEBOL? Os resultados apontaram a utilização dos domínios GUERRA, ARTE, RELIGIÃO, JOGOS DE AZAR, ALIMENTO, VIDA, CONTÊINER, MÁQUINA e NAÇÃO na imprensa mineira para falar do domínio FUTEBOL.

PALAVRAS-CHAVE: Futebol; Metáfora; Cognição.
\end{abstract}

\section{METAPHOR AND SOCCER IN THE PRESS FROM MINAS GERAIS}

\begin{abstract}
This article presents metaphoric as well as metonymic language presented by the press from Minas Gerais, Brazil in the sports news. We analyzed metaphors and metonymies motivated by different experiential domains to talk about soccer. The analysis focused on data collected in newspapers from Belo Horizonte, Minas Gerais using as theoretical framework Conceptual Metaphor Theory. Our research question was: which experiential domains will map onto the domain SOCCER? Results pointed out the use of the domains WAR, ART, RELIGION, GAMES OF CHANCE, FOOD, LIFE, CONTAINER, MACHINE and NATION in the press from Minas Gerais in order to talk about the domain SOCCER.

KEYWORDS: Soccer; Metaphor; Cognition.
\end{abstract}

\section{A METÁFORA/A METONÍMIA}

A metáfora, sua função retórica e o seu papel na cognição humana sempre despertaram o interesse de estudiosos da linguagem. Aristóteles (2000) considera a metáfora como um tipo de linguagem nobre e elevada que emprega termos raros. Segundo a visão clássica, a metáfora seria um tropo, uma figura de linguagem, um desvio da norma que refere outro significado que não o literal com um objetivo estético. Mahon assinala que "Aristóteles adota uma posição acerca da onipresença da metáfora na conversa e escrita que apóia visões atuais sobre a onipresença da metáfora no discurso cotidiano e na mídia impressa” (MAHON, 1999, p. 69).

1 Este projeto recebeu apoio de uma bolsa PIBIC/PROBIC, Fundação de Amparo à Pesquisa de Minas Gerais (FAPEMIG) em 2011/2012. Agradeço à minha bolsista IC Catarina Flister pelo apoio. Esse artigo foi finalizado durante estágio pós-doutoral na University of California, Santa Cruz (UCSC) em 2014/2015 (Agência CAPES, processo BEX 1825/14-3) e os resultados apresentados no CSDL na UC Santa Bárbara em novembro de 2014. 
Lakoff \& Johnson (1980) propõem que nosso pensamento é estruturado por meio de mapeamentos metafóricos. De acordo com esses autores, quando usamos metáforas em nosso discurso cotidiano, conceituamos uma coisa em termos de outra, lançando mão de conceitos mais concretos para explicar conceitos mais abstratos (LAKOFF \& JOHNSON, 1980). Tal proposta foi reformulada posteriormente, sugerindo que, ao utilizarmos metáforas, estabelecemos relações de semelhança entre os conceitos ou imagens, destacando os aspectos percebidos que apresentam relações de similaridade (GRADY, 1997). O uso de metáforas/metonímias no discurso visa a destacar algum aspecto do que se fala de maneira criativa, ocultando outros, considerados pelo falante como menos importantes. Por meio desse uso específico da linguagem, busca-se suscitar no interlocutor um grande impacto cognitivo, à medida que esse interlocutor vai associar tal informação com o contexto discursivo mais relevante que lhe é acessível naquele determinado momento e entorno social. Eis porque a metáfora/metonímia assume um papel de destaque no discurso da mídia e é amplamente utilizada no discurso da mídia sobre futebol. A metonímia é um mapeamento que ocorre dentro de um mesmo domínio cf. Kövecses (2010), estabelecendo diferentes tipos de relações entre esses domínios, por exemplo LUGAR POR EVENTO e LUGAR PELA INSTITUIÇÃO, como é o caso quando se usa ‘casa’ para falar de ‘estádio’ (2010, p. 173).

Veja a seguir como o escritor mineiro Carlos Drummond de Andrade escreveu sobre a Copa do Mundo utilizando metáforas e metonímias no texto intitulado "Explosão", que foi publicado no Jornal do Brasil em 1982:

\footnotetext{
Se a gente ganha a Copa do Mundo, este país explode. Se perder, explode também. Não há alternativa. No primeiro caso, ainda haverá a tentativa oficial de convocar os campeões da Taça Jules Rimet para governarem o Brasil, sob o comando do General de 11 estrelas Telê Santana. Mas sem resultado. Cada brasileiro se sentirá campeoníssimo e há de querer governar, sozinho, pelo menos a América Latina, ou a Europa - e o Brasil ficará, desculpem, desgovernado. No segundo caso... Cala-te, boca (DRUMMOND DE ANDRADE, 2002, p. 163).
}

Drummond escreve que o Brasil 'explode', fazendo uma alusão às fortes emoções experienciadas pelos torcedores ao assistir um jogo de futebol, especialmente quando joga a seleção brasileira. $\mathrm{O}$ autor também refere o contexto de uso em que tal enunciado e tal jogo se inserem, que é a ditadura militar ainda no poder em 1982, utilizando a metonímia 'estrelas' para falar dos jogadores e utilizando uma metáfora de semelhança para referir o trabalho do técnico, que é semelhante ao trabalho de um General de exército. Drummond nos fornece um belo exemplo de como a metáfora está em toda parte e pode ser veiculada com objetivos diversos. No caso de seu texto, a metáfora e a metonímia foram usadas para provocar um efeito humo- 
rístico no seu leitor e a metáfora primária INTENSIDADE DE EMOÇÕES É CALOR licencia as metáforas de emoções no texto cf. o quadro proposto por Kövecses (2010, p. 144):

Tabela 1 - Mapeamento Metafórico

$\begin{array}{ll}\text { Fonte } & \\ \text { O que esquenta } & \rightarrow \text { A entidade envolvida na situação } \\ \text { Ofogo } & \rightarrow \text { A situação (ação, evento, estado) } \\ \text { O calor do fogo } & \rightarrow \text { A intensidade da situação } \\ \text { A causa do fogo } & \rightarrow \text { A causa da situação }\end{array}$

Essa metáfora conceptual foi originalmente estudada por Grady (1997) que propõe que metáforas conceituais primárias envolvem uma ligação entre conceitos distintos que surgem de cenas primárias e suas correlações. Segundo esse autor, os conceitos fonte de metáforas primárias têm um conteúdo relacionado à percepção física ou à sensação. Por exemplo, quando abraçamos alguém ou - estamos próximos de alguém que está se escondendo em uma brincadeira de criança, 'estamos quentes'. Essa expressão metafórica é a realização linguística de uma metáfora conceptual, PROXIMIDADE É CALOR, que, no caso, seria primária e foi motivada por uma experiência muito básica para todos os seres humanos desde que nascemos, que é o calor experienciado no colo materno.

Outro aspecto importante explorado no exemplo acima é o que Kövecses (2010) denomina de "criatividade induzida pelo contexto" (context-induced creativity). Por meio desse conceito, Kövecses explica como a escolha de um domínio-fonte específico para um novo mapeamento é motivada por fatores contextuais, dentre eles, o contexto cultural imediato, o contexto social em que a linguagem figurada é enunciada, assim como o lugar em que o enunciado metafórico é proferido e o que sabemos sobre os participantes do discurso em questão.

Para os linguistas cognitivos, a linguagem reflete aspectos do sistema conceitual humano, motivado pela cognição corpórea (GIBBS, 2006). Padrões sistemáticos de estrutura e comportamentos linguísticos são motivados por padrões recorrentes de experiência corpórea. Nessa linha, metáforas conceituais como ‘bom é para cima' e 'ruim é para baixo’ estruturam o nosso pensamento e irão motivar expressões linguísticas como 'ela é uma pessoa para cima', significando ela é uma pessoa feliz, assim como 'isso foi uma baixaria', significando uma ação avaliada como negativa pelo falante. Portanto, para os linguistas cognitivos, o significado não é arbitrário, mas motivado pelo modo como nosso corpo se desloca no ambiente e intera- 
ge com outros objetos no mundo, e isso se reflete na linguagem. Tal reflexão de que o nosso raciocínio e a nossa compreensão são estruturados por metáforas foi muito bem sistematizada por Lakoff e Johnson (1980) em seu trabalho seminal, representando um marco na área de estudos da metáfora. Esses autores propõem claramente, a partir de um vasto inventário de expressões metafóricas abstraídas a partir da língua em uso, que metáforas conceituais são o mapeamento de aspectos de um domínio de experiência, o domínio-fonte, geralmente mais concreto, em termos de aspectos não-metafóricos de um outro domínio, o domínio-alvo, geralmente mais abstrato. Depois que se aprende um mapeamento metafórico, ele se torna convencionalizado e é usado automaticamente.

O objetivo do presente estudo é analisar como a mídia de Minas Gerais, mais especificamente os jornais O Tempo e Estado de Minas, utiliza expressões metafóricas e metonímicas motivadas por outras experiências para falar sobre o futebol de maneira criativa, como veremos a seguir.

\section{COGNIÇÃO E A COMPREENSÃO DE METÁFORAS/METONÍMIAS}

Além da dificuldade de se determinar qual é a metáfora/metonímia conceitual a partir da análise sistemática de expressões convencionais, há também o problema de se descobrir como as inferências, i.e. correspondências de determinada metáfora/metonímia conceitual, são criadas e armazenadas. Tendo como ponto de partida um corpus de conversas sobre câncer, Semino et al. (2004) discutem problemas metodológicos encontrados ao identificar e analisar metáforas. Os autores demonstram como diferentes decisões no processo de análise teriam conduzido a conclusões distintas sobre a maneira como o câncer parece ser construído metaforicamente nos dados. Segundo eles, há duas possibilidades diferentes de percursos analíticos para a mesma metáfora, dependendo da escolha do domínio-alvo ser CÂNCER ou CÂNCER FICANDO ATIVO. Nesse caso, o câncer é conceitualizado como um vulcão, pois o câncer é mencionado como 'entrando em erupção' e posteriormente como estando 'adormecido' na conversa entre médico e paciente (SEMINO et al., 2004, p. 1281). Em outro trecho da conversa, o câncer é conceitualizado como um cavalo que está 'galopante'. Semino et al. chegam a afirmar que o exemplo ‘adormecido' pode acionar os dois mapeamentos simultaneamente, i.e. CÂNCER É ANIMAL e CÂNCER É VULCÃO. Isso seria uma evidência de que esses con- 
ceitos são convencionalmente mapeados em outros domínios, além dos domínios com os quais o seu significado é associado.

Em outro estudo sobre compreensão metafórica, Gibbs e Ferreira (2011) investigaram se os participantes entendem umas, algumas ou todas as correspondências, i.e. acarretamentos associados com a metáfora conceitual quando processam expressões metafóricas convencionais motivadas por determinada metáfora conceitual. A literatura na área de Linguística Cognitiva não apresenta uma resposta para tal pergunta porque ela nunca havia sido arrolada anteriormente. Já sob uma perspectiva psicolinguística, provavelmente existam várias respostas, dependendo do momento da compreensão analisado. Outro objetivo do estudo foi descobrir porque algumas correspondências de metáforas conceptuais estão mais relacionadas do que outras. Por exemplo, ao ouvir o enunciado metafórico "Ela lutou contra a sua raiva", perguntou-se se o indivíduo reconhecia que as várias correspondências associadas com a metáfora conceitual RAIVA É UM OPOSITOR (em uma briga) (LAKOFF, 1987, p. 392) estavam implicadas. Ou se o sujeito ao ler "Ela lutou contra a sua raiva", julgava expressões como "Ela explodiu de raiva" ou "Ela ficou cheia de raiva" como não sendo relacionadas com a primeira, porque elas são motivadas por uma metáfora conceitual distinta que é RAIVA É UM LÍQUIDO AQUECIDO EM UM RECIPIENTE (KÖVECSES, 2005, p. 39), embora elas se refiram ao mesmo domínio-alvo RAIVA, mas têm um domínio-fonte diferente (RECIPIENTE) que dá origem a um conjunto diferente de correspondências do que para a metáfora conceitual RAIVA É UM OPOSITOR (em uma briga). A hipótese preditiva foi de que itens com uma metáfora conceitual, metáfora linguística e correspondência consistentes, por exemplo, o enunciado metafórico "Ela ficou cheia de raiva" combinado com "sentir raiva é como sentir uma substância ou objetos contidos em um recipiente", cuja metáfora conceitual é RAIVA É UM LÍQUIDO AQUECIDO EM UM RECIPIENTE, assim como itens que têm enunciados metafóricos com um domínio-fonte comum, tal como OPOSITOR em "Ela lutou contra a sua raiva" ou "Ela foi dominada pela sua raiva" seriam julgados com uma pontuação mais alta. Por outro lado, também foi previsto que os sujeitos, ao lerem enunciados metafóricos com domíniosfonte diferentes e, portanto, não relacionados, como "Ela ficou cheia de raiva" (DF: RECIPIENTE) não conseguiriam associá-los à correspondência "o indivíduo luta contra a raiva, assim como luta contra o opositor em uma briga" (DF: OPOSITOR). Os resultados apontam que os participantes envolvidos no estudo julgaram com pontuação maior os enunciados metafóricos com as correspondências consistentes do que os não relacionados. Isso sugere que os indivíduos parecem reconhecer que uma expressão metafórica implica certos significados rela- 
cionados à metáfora conceitual subjacente, embora a compreensão de metáforas verbais não pareça implicar diretamente correspondências com o domínio-alvo que emergem de metáforas conceituais distintas, como é o caso das duas metáforas conceituais com o domínio RAIVA. Tal resultado constitui evidência de que as pessoas conseguem inferir ao menos uma pequena gama de correspondências motivadas por uma metáfora conceitual subjacente quando leem enunciados metafóricos convencionais.

Tal estudo revela como um domínio-alvo experiencial, como FUTEBOL no caso dessa pesquisa, pode vir a ser motivado por vários domínios-fonte distintos, licenciando diferentes metáforas conceituais que refletem diferentes aspectos do domínio-fonte FUTEBOL. Tal possibilidade certamente tem como implicação a dificuldade de se determinar a metáfora conceitual que motiva uma expressão metafórica.

\section{METÁFORAS DE FUTEBOL NA CULTURA BRASILEIRA E EM OUTRAS CULTURAS: EVIDÊNCIAS INTERLINGUÍSTICAS}

A experiência com o futebol está entrincheirada na cultura brasileira e isso se reflete no nosso falar cotidiano. Se algo não correu como se esperava, então "deu na trave". Se alguém não quer mais namorar, então "dá um cartão vermelho" para o parceiro, utilizando expressões do domínio experiencial do futebol para falar das emoções. De acordo com o experiencialismo, a linguagem figurada de uma comunidade pode ser encarada como reflexo dos padrões convencionais de pensamento e visões de mundo daquela comunidade (LAKOFF, 1987). Assim, a maneira como o brasileiro conceitualiza suas experiências cotidianas é amplamente influenciada pela experiência com o futebol, avaliado pelos entrevistados em uma pesquisa da Folha de São Paulo (20/10/2010) como o terceiro elemento que melhor qualifica a cultura brasileira, depois da Música Popular Brasileira e do carnaval.

A relação entre cultura e lingua(gem) é fundamental para que possamos compreender os universos sociodiscursivos em que determinado grupo social se situa. Sabemos, a partir de Duranti (1997) que, para entendermos determinada cultura, faz-se necessário que entendamos sua língua. Assim, língua é compreendida através de sua relação com as práticas discursivas que formam a cultura e, tais práticas, por sua vez, realizam-se através da interação entre indivíduos e grupos sociais. Quando se refere à base cultural da metáfora, Gibbs (1999) destaca que antropólogos e linguistas defendem que a presença de metáforas em expressões linguísti- 
cas refletiria tanto a operação de estruturas mentais individuais, como também o trabalho de diferentes modelos culturais. Tais modelos culturais são definidos pelo autor como esquemas culturais subjetivamente compartilhados que funcionam no intuito de interpretar experiências e guiar ações em vários domínios, incluindo eventos, instituições e objetos mentais e físicos. Kövecses discorre sobre o papel da cultura na conceitualização metafórica: “[...], as mentes que evoluem 'em cérebros' em determinadas culturas são moldadas pelos diferentes contextos (histórico, físico, discursivo, etc) que, em parte, constituem as culturas. Isso leva a sistemas conceituais alternativos" (KÖVECSES, 2010, p. 741). Dessa forma, modelos culturais são interpretados como uma representação de visão de mundo de uma sociedade/cultura/grupos sociais no tocante às suas crenças, atos, socioletos e experiências de mundo. Tal relação entre metáfora e cultura é ressaltada também por Lakoff e Johnson (1980), uma vez que as metáforas estruturariam o sistema conceitual humano, o qual, por sua vez, estaria edificado sobre as bases da cultura. Assim sendo, se metáforas são criadas dentro de contextos comunicativos, logo, elas variam de uma cultura para outra e, consequentemente, de uma língua para outra.

Porto \& Romano (2013) destacam o papel do contexto na criação e desenvolvimento do uso de expressões metafóricas na mídia espanhola e britânica durante a crise econômica a partir de 2009 na Espanha e durante a erupção do vulcão Eyjafjallajökull em 2010. O presente estudo se situa nessa mesma linha, buscando estudar os efeitos da metáfora no discurso e o papel do contexto na sua compreensão e função. Um estudo de Semino \& Maschi (1996) revelou como Silvio Berlusconi se alinhou com os eleitores italianos, usando o seu conhecimento sobre futebol e seu poder como dono do A. C. Milan, a fim de fazer oposição à esquerda e ganhar as eleições italianas no início dos anos noventa. Esses autores constataram que Berlusconi utilizou os domínios experienciais FUTEBOL, GUERRA e RELIGIÃO para falar do domínio-alvo POLÍTICA.

Nessa linha, expressões metafóricas refletem o domínio experiencial futebol, tanto como fonte para falar de outro domínio da experiência humana, como é o caso da metáfora POLÍTICA É FUTEBOL, utilizada especialmente pelo ex-presidente Lula para referir a composição de seu ministério, comparando-o com as posições em um time de futebol, tendo ele como técnico da equipe (MACHADO, 2010), como quando o deputado Eduardo Suplicy deu um cartão vermelho para o Senador Sarney no Senado (Ferreira e Gonçalves, 2011). Isso também ocorre quando usamos elementos de outro domínio experiencial para falar de futebol, como o faz o técnico Scolari ao afirmar "É guerra. Tenho que matar para não morrer" (The Sun, 19.6.2004), expressão metafórica licenciada pela metáfora conceitual FUTEBOL É 
GUERRA, por meio da qual Scolari descreve metaforicamente a vitória do seu time contra outro time. Gibbs afirma em seu livro The Poetics of Mind (1994) que toda metáfora reflete um aspecto diferente da percepção de alguma experiência. Nesse sentido, as expressões que vamos encontrar na mídia brasileira refletem aspectos da cultura brasileira e da experiência dos brasileiros com o futebol que são necessariamente diferentes das experiências de outros povos com o futebol, como apontam os dados de Almeida e Sousa (2013) em um estudo sobre metáforas na mídia portuguesa e alemã, assim como os dados de Ferreira e Gonçalves (op. cit.) sobre metáforas na mídia alemã e brasileira.

Tanto na mídia brasileira como na mídia alemã à época da Copa do Mundo da FIFA 2010, na África do Sul, foram encontradas evidências do domínio futebol motivando o domínio política na mídia brasileira e alemã. Contudo, na mídia alemã, outros domínios experienciais também foram utilizados para se falar de política, como GUERRA, JOGOS DE AZAR (CARTAS) e MÁQUINAS. Na mídia brasileira, foram identificados os seguintes domínios para se falar sobre futebol: GUERRA, RELIGIÃO, NAÇÃO, POLÍTICA, ARTE, MÁQUINA e ALIMENTO, enquanto na mídia alemã há evidências dos domínios GUERRA, ARTE e NEGÓCIOS. Na mídia alemã, quando o futebol é conceitualizado como ARTE, jogadores são descritos como 'bailarinos' e o futebol como uma 'obra de arte' e como 'mágica', o que Almeida (2013) denomina de domínio conceitual FANTÁSTICO para se falar de futebol. Durante os dois meses da coleta de dados, i.e. maio e junho de 2010, metáforas de futebol foram mais produtivas no domínio-alvo POLÍTICA no português brasileiro do que em alemão (FERREIRA e GONÇALVES, 2011). Não foi encontrada nenhuma expressão metafórica motivada pelo domínio experiencial RELIGIÃO durante a Copa de 2010 na mídia alemã no período estudado (06.07.2011 a 15.07.2011). Foram analisados os diários Die Welt e Berlin Morgenpost, assim como a revista semanal Der Spiegel. Em um estudo comparativo sobre reportagens da mídia alemã e brasileira sobre futebol durante a Copa do Mundo de Futebol Feminino, realizada na Alemanha em 2011, foram encontradas somente na mídia brasileira expressões metafóricas cuja metáfora conceitual subjacente é FUTEBOL É RELIGIÃO.

Almeida e Sousa (2013) fizeram um levantamento das ocorrências de metáforas conceituais, cujo domínio-alvo foi futebol, nos títulos de reportagens sobre o tema publicadas no jornal desportivo português $A$ Bola entre os anos de 2003 e 2007. As autoras encontraram 138 exemplos (p. 71), divididos entre os seguintes domínios experienciais: GUERRA, NATUREZA e TECNOLOGIA. Esse domínio foi em parte conceitualizado como MÁQUINA na classificação das metáforas no português brasileiro, por exemplo, ao conceitualizar os jogadores 
como 'peças' de uma engrenagem, que seria o time. O domínio GASTRONOMIA, usado por Almeida e Sousa (2013), foi denominado ALIMENTO, ARTE e ECONOMIA nos dados do português brasileiro.

Estudos apontam que expressões metafóricas para descrever esportes e jogos frequentemente são motivadas pelos domínios experienciais ARTE, GUERRA, RELIGIÃO e VIOLÊNCIA (SIMÓ, 2008). Por exemplo, quando um repórter afirma que "a torcida não conseguia ver sangue durante o jogo" ${ }^{2}$, o domínio experiencial VIOLÊNCIA é ativado a fim de descrever a experiência abstrata de sofrimento envolvida quando os fãs assistem a um jogo de futebol. Simó (op. cit.) distingue entre o domínio experiencial VIOLÊNCIA e GUERRA na conceitualização do jogo de xadrez, pois a autora argumenta que nem todas as expressões do domínio experiencial GUERRA, utilizadas para falar do esporte, são violentas, mas sim se referem à estratégia. $\mathrm{O}$ mesmo se aplica ao futebol, pois falamos de tática, ataque e defesa em futebol, e tais conceitos não estão necessariamente relacionados a atitudes violentas no campo.

Tanto os dados do português brasileiro, levantados por Ferreira e Silva (2014) como os dados sobre o português europeu, apresentados por Almeida e Sousa (2013), agregam evidências à afirmação de Simó (2008) de que expressões metafóricas para descrever esportes e jogos frequentemente são motivadas pelos domínios experienciais ARTE, GUERRA e RELIGIÃO. Talvez aqui uma diferença na conceitualização dos domínios seja a causa para diferenças entre os dados do português brasileiro e europeu. Por exemplo, TECNOLOGIA, foi denominado como MÁQUINA, aplicando-se somente à parte dos dados na classificação das metáforas no português brasileiro. O domínio GASTRONOMIA foi denominado ALIMENTO nos dados do português brasileiro, e o domínio-fonte SOBRENATURAL que, na classificação de Almeida e Sousa (op. cit.) engloba os subdomínios RELIGIÃO e FANTÁSTICO foi, nos dados brasileiros, em parte classificado por meio dos domínios conceituais RELIGIÃO e ARTE. O domínio RELIGIÃO motiva expressões como 'ter fé' em um time, em que conhecimentos do domínio religião estão sendo usados para falar de futebol. O domínio ARTE motiva expressões como 'elenco' para falar do time e 'dança' para falar dos movimentos dos jogadores em campo.

2 DVD Penta a hegemonia do Flamengo, 2009. 
Foram apresentados aqui vários estudos que revelam o uso de metáforas para se falar sobre o futebol no discurso cotidiano em diferentes idiomas e culturas. A seguir apresentaremos a metodologia adotada no presente estudo.

\section{METODOLOGIA}

Este é um estudo de natureza qualitativa. Realizou-se uma análise indutiva, a partir da observação de instâncias de metáforas e metonímias para se proceder à descrição de sistemas conceituais, partindo-se de regularidades observadas na língua em uso. Fez-se um tipo de análise bottom-up, i.e. do discurso para o pensamento, a partir de metáforas linguísticas identificadas em textos da mídia e, a partir, daí, foram agrupadas metáforas lingüísticas, cuja metáfora conceitual é comum.

Os dados foram coletados na mídia impressa de Minas Gerais, mais especificamente nos jornais O Tempo e Estado de Minas (Super) no período de 8.07.2011 a 02.09.2011 e examinados manualmente pelo analista ${ }^{3}$. Seguiu-se os procedimentos metodológicos descritos em Lakoff \& Johnson $(1980,1999)$ e Kövecses (2010) na identificação das metáforas e metonímias conceituais que licenciam as expressões metafóricas/metonímicas observadas nos dados. Os procedimentos adotados para a análise das metáforas e metonímias foram os seguintes:

1) Identificação das expressões metafóricas nos textos em jornais;

2) Identificação dos domínios conceituais das metáforas;

3) Determinação da metáfora conceitual de cada expressão metafórica analisada no estudo.

Foram examinadas manchetes e seus respectivos textos da coluna de esportes dos respectivos jornais de Minas Gerais. Fez-se a opção por extrair e investigar as expressões metafóricas em seu contexto discursivo, pois, como apontam Porto \& Romano (2013), "o texto principal que segue é igualmente importante, à medida que constitui o contexto discursivo maior e o quadro (frame) das metáforas, [...]. Tais textos foram especialmente úteis na identificação de expressões metafóricas novas ou de novos usos das expressões metafóricas já exis-

3 Com o auxílio de uma bolsista PIBIC/PROBIC, Fundação de Amparo à Pesquisa de Minas Gerais (FAPEMIG) em 2011, Bárbara Gonçalves. 
tentes" (p. 63). Foram encontradas um total de 62 ocorrências metafóricas (cf. Fig. 1 a seguir $5 \%$ das expressões encontradas foram metonímias) que estão representadas na figura 1 :

Fig. 1 - Percentual de ocorrências de diferentes domínios conceituais

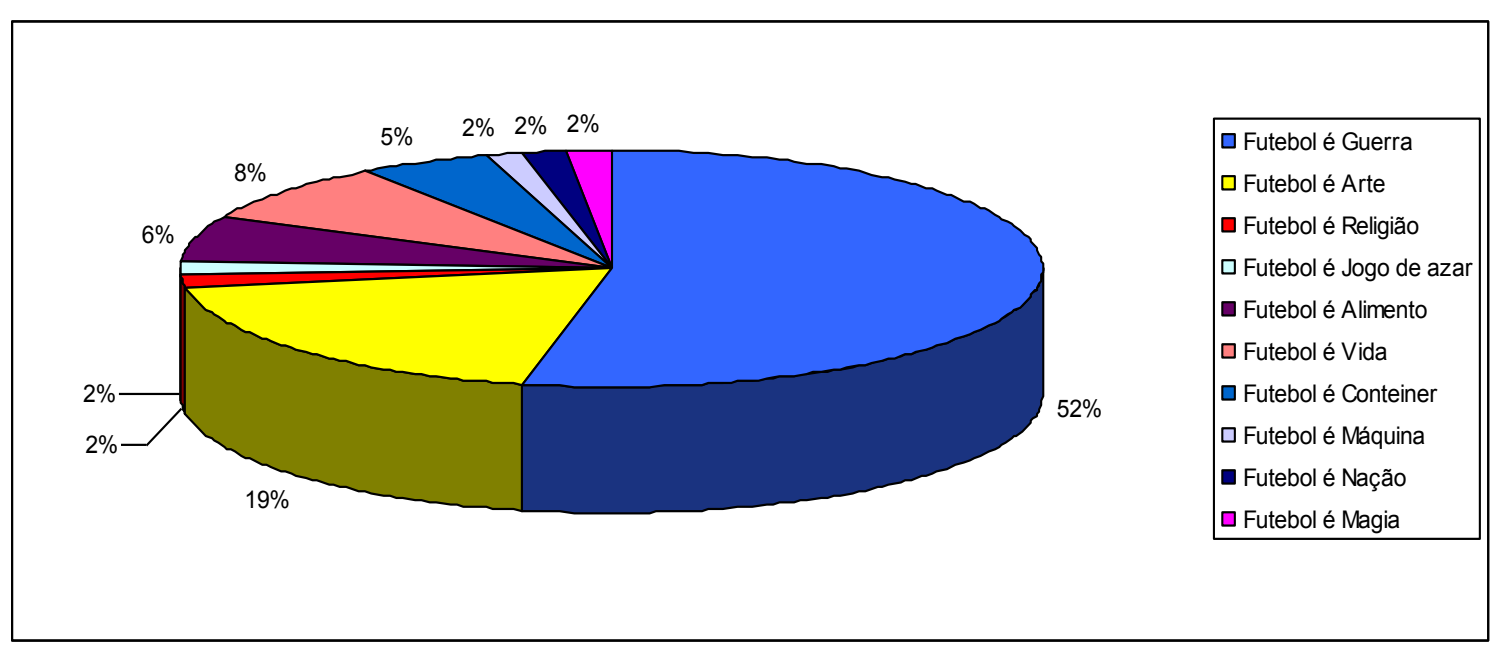

A seguir apresentaremos evidências linguísticas retiradas da mídia, mais especificamente de jornais da cidade de Belo Horizonte, a fim de ilustrar como o futebol é descrito na mídia de Minas Gerais por meio de uma diversidade de metáforas, motivadas por diferentes domínios conceituais.

\section{RESULTADOS E ANÁLISE DE DADOS}

Foram encontradas um total de 62 ocorrências no período, que foi de 8.07.2011 a 02.09.2011, nos dois jornais mineiros de maior circulação, O Tempo e o Estado de Minas (Super), que serão discutidas na sequência.

\subsection{FUTEBOL É GUERRA}

Foram encontradas 33 expressões metafóricas motivadas por esse domínio experiencial. Quando um repórter afirma que "os fãs não conseguiram ver sangue durante o jogo", o domínio GUERRA é ativado, a fim de descrever a experiência abstrata de sofrimento envolvida quando os fãs assistem a um jogo de futebol. Portanto, a metáfora conceitual ativada aqui é 
FUTEBOL É GUERRA. Franco Jr. escreve que "futebol é guerra simbólica” (FRANCO Jr, 2007, p. 236), destacando varias expressões metafóricas do domínio GUERRA utilizadas no futebol. O jogador que ocupa a função de fazer gols é o 'artilheiro', o 'matador' é o carrasco dos adversários e o representante do time perante o juiz é denominado segundo uma patente militar, i. e. o 'capitão' do time. Nessa linha, o treinador do time é designado como 'general', 'comandante', já que determina as regras a serem seguidas pela 'legião', i.e. os jogadores do time, destacando a importância das virtudes militares da camaradagem e da disciplina e fazendo com que a equipe siga regras na 'concentração', o lugar onde os jogadores se reúnem para se preparar física e psicologicamente antes do jogo, outro termo que alude à Segunda Guerra Mundial.

A seguir, alguns exemplos de como metáforas de GUERRA foram veiculadas na mídia no contexto do Campeonato Brasileiro:

(1) “[...] é o que o técnico Cuca quer que seus comandados mentalizem para o retorno do Campeonato Brasileiro [...]" (O Tempo, 2/09/2011, p. 42).

(2) "[...], destacou o comandante, mencionando o triunfo por 3 a 0 sobre o Fluminense" (Estado de Minas, Super Esportes, 16/08/2011, p. 3).

(3) "Ele começou a perder o comando quando os dirigentes entenderam que não havia mais espaço no futebol para um técnico mais amigo do que comandante ou mais pai do que treinador" (Estado de Minas, Super Esportes, 03/09/2011, p. 1).

(4) "[...], tem 13 jogos no comando celeste [...]" (Estado de Minas, Super Esportes, 28/08/2011, p. 5).

(5) "[...] a situação do Atlético mexe com uma legião de torcedores espalhados pelos quatro cantos do mundo" (O Tempo, 2/09/2011, p. 38).

Alguns jogadores mais ativos durante a partida são chamados de 'guerreiros' e a própria partida é chamada de 'duelo', 'confronto', 'peleja' e 'embate'. Os jogadores usam suas 'armas', fazem 'treinamentos' e são 'rivais', ainda que, na mesma linha de argumentação de Haser (2005), pode-se afirmar que rivalidade, treinamento e ofensiva caracterizam qualquer tipo de jogo ou competição, e não são características exclusivas do domínio experiencial futebol.

A seguir, temos alguns exemplos que referem o Campeonato Mineiro e outros cujo quadro (frame) é o Campeonato Brasileiro. Todas as metáforas apresentadas a seguir são metáforas convencionais amplamente veiculadas na imprensa sobre futebol.

(6) "[...], o Coelho chegou a levar perigo nas cobranças de bola parada" (O Tempo, 2/09/2011, p. 41).

(7) “[...] o encontro entre os dois rivais históricos provoca o mesmo frisson?" (Estado de Minas, Super Esportes, 26/08/2011, p. 3). 
(8) “Já o Cruzeiro tem muitos jogadores com larga experiência no duelo, [...]" (Estado de Minas, Super Esportes, 26/08/2011, p. 4).

(9) "Mostrando ter conhecimento do mais tradicional confronto mineiro ele promete buscar inspiração em atacantes como [...]" (Estado de Minas, Super Esportes, 26/08/2011, p. 4).

(10) "Mas preparou armas durante os treinamentos secretos, [...]" (Estado de Minas, Super Esportes, 28/08/2011, p. 5).

(11) "[...] Na busca do aumento do poder ofensivo para superar a Ponte Preta" (Estado de Minas, Super Esportes, 16/08/2011, p. 5).

(12) "Diego Renan não enfrentou o Atlético-PR no ano passado, [...]" (Estado de Minas, Super Esportes, 16/08/2011, p. 5).

(13) “[...] a Ponte Preta pode recolocar o Boa na briga por um lugar no G4" (Estado de Minas, Super Esportes, 16/08/2011, p. 5).

(14) “Confronto direto/As armas de cada um" (Estado de Minas, Super Esportes, 28/08/2011, p. 4).

(15) "Ao contrário do rival, esse time mantém uma base, [...]" (Estado de Minas, Super Esportes, 28/08/2011, p. 4).

(16) "Atlético e Cruzeiro se enfrentam hoje, às 18h, na Arena do Jacaré, em Sete Lagoas, pela 19a. rodada, buscando a redenção" (Estado de Minas, Super Esportes, 28/08/2011, p. 4).

Note-se que várias fases da GUERRA se refletem no discurso sobre o futebol, desde 'preparar as armas' que seria a preparação para o 'confronto' até o 'embate' e, por fim, a 'redenção'. Tratam-se de evidências que parecem atestar a existência de um domínio FUTEBOL bastante bem delineado. A arena onde ocorre o jogo de futebol é decorada com escudos e bandeiras, e lá se ouvem hinos e 'gritos de guerra' das torcidas. Algumas torcidas chegam a levar nomes como 'Exército Gremista' e 'Pavilhão 9', torcidas respectivamente dos times Grêmio, de Porto Alegre, e Corinthians, de São Paulo, que aludem claramente ao contexto da prisão e do domínio militar.

Tal riqueza de dados discursivos possibilita ter uma idéia das diferentes facetas do domínio GUERRA, ressaltando aspectos a partir dos quais o futebol é percebido por meio de metáforas de semelhança (GRADY, 1997) que vão licenciar metáforas discursivas como 'comando','armas', 'confronto', 'rival' e outras que aparecem contextualizadas acima. Expressões metonímicas como ‘armas' e metafóricas como ‘duelo' vão destacar alguns aspectos do jogo, como o confronte entre equipes rivais, e deixar de lado outros aspectos, por exemplo, do jogo como uma festa de confraternização entre equipes adversárias. Tal potencial da metáfora e da metonímia para destacar alguns aspectos de um domínio experiencial são amplamente 
utilizados no discurso da mídia, também da mídia desportiva, a fim de provocar um grande impacto cognitivo no seu leitor.

A seguir serão apresentadas evidências de outro domínio experiencial bastante utilizado no português brasileiro para se falar de futebol, que é ARTE.

\subsection{FUTEBOL É ARTE}

Foram encontradas 12 expressões metafóricas motivadas por esse domínio experiencial no mesmo período de tempo do estudo. A importância das artes na cultura brasileira também se reflete nas maneiras de falar sobre o futebol no português brasileiro que é conceitualizado como 'futebol arte', fazendo uma alusão ao artigo clássico em que Pier Paolo Pasolini descreve o futebol brasileiro na Copa de 70 como 'futebol poesia', comparando-o com o futebol italiano que seria o 'futebol prosa' (WISNIK, 2007). O 'futebol poesia' é a dança dos jogadores sul-americanos, idéia veiculada por meio de expressões que aludem ao mundo do teatro e do cinema, como 'grandes atuações', 'elenco', 'roteiro', 'estreia' para descrever o futebol brasileiro, como se pode ver nos exemplos que seguem:

(17) "Ele treinou muito durante a semana e se depender de seu futebol o encanto será quebrado: a primeira vitória do argentino diante do maior rival" (Estado de Minas, Super Esportes, 28/08/2011, p. 4).

Tal exemplo suscita uma discussão frequente entre os estudiosos da metáfora, que é qual metáfora conceitual irá licenciar a expressão metafórica acima, que claramente pertence ao subdomínio da MAGIA e do FANTÁSTICO. Almeida e Sousa (2013) referem o domínio do SOBRENATURAL (ALMEIDA; SOUSA, 2013, p. 86), em que se encaixaria também o domínio RELIGIÃO. Enquanto o rito futebolístico tem uma relação mais estreita com a MAGIA, e isso explicaria as superstições ligadas ao futebol, i.e. o uso de amuletos para trazer boa sorte e a crença de que alguma atitude pode trazer azar para o time ${ }^{4}$ ou para o jogador. Portanto, o jogo de futebol apresenta inúmeras referências religiosas. Franco Jr. (2007) escreve que o espaço do ritual é o estádio que seria o santuário do mundo industrial e, assim como se construíam igrejas nas cidades européias na Idade Média, hoje são construídos grandes templos do futebol, nos países onde o futebol é importante, como o Brasil.

4 Veja-se fala de torcedor no filme Fiel, acesso em 23.02.2014, hora $12.27<$ https://www.youtube.com/ watch? $\mathrm{v}=\mathrm{mrPn} 4 \mathrm{TGkLx} 4>$. 
É comum no Brasil os clubes terem um patrono, um santo protetor, por exemplo, São Jorge é o patrono do Corinthians. Seguindo essa linha de raciocínio, a camisa é chamada de 'manto sagrado' e os estádios de futebol são 'templos' do futebol, os torcedores carregam a imagem de São Judas Tadeu vestindo um manto com a bandeira do Flamengo em dia de jogo. Portanto, a própria referência ao estádio de futebol como sendo um 'templo' é uma referência ao domínio experiencial RELIGIÃO, assim também como chamar a camisa do time de 'manto sagrado' é outra referência ao domínio experiencial RELIGIÃO para se falar de FUTEBOL.

Antes de entrar em campo no Brasil, frequentemente os jogadores fazem o sinal da cruz e pedem proteção. A cultura brasileira e a religiosidade do povo brasileiro também têm seus reflexos no campo, de modo que os torcedores e técnicos têm 'fé':

(18) "Tenho fé no nosso trabalho e no que temos feito durante as últimas semanas [...]" (Estado de Minas, 08.07.2011).

Os times fazem um ‘jejum’ quando deixam de jogar:

(19) "O representante mineiro na competição quebrou sexta-feira à noite jejum de três partidas sem vitória [...]” (Estado de Minas, Super Esportes, 28/08/2011, p. 2).

Novamente tem-se a possibilidade de utilizar dois domínios experienciais como motivadores da metáfora conceitual, como no estudo de Semino et al. (2004) sobre a conceitualização do câncer como um VULCÃO ou como um ANIMAL. No exemplo (19), o domínio futebol pode ser visto como conceitualizado em termos de ALIMENTO, nesse caso seria o mesmo domínio experiencial ALIMENTO/COMIDA que motiva a expressão metafórica 'vitoria magra', ou de RELIGIÃO. Embora o futebol tenha várias referências religiosas, no período observado foram registradas poucas ocorrências, de modo que se optou por agrupar o domínio religião junto ao domínio ARTE. Ao discorrer sobre o futebol como dança, Franco Jr. ressalta que "o caráter sagrado da dança é com frequência reforçado por cantos e encantos" (FRANCO Jr, 2007, p. 228).

Conceitos do domínio ARTE vão descrever um cenário em que o futebol é o palco para 'história' com um 'elenco' e um 'roteiro' pré-determinado. Fala-se do futebol 'espetáculo', cujo 'elenco' tem uma 'estreia', cujos atores, i.e. jogadores irão 'buscar inspiração' para uma grande 'atuação'. 
(20) "As grandes atuações renderam a Fábio mais uma convocação para a seleção" ( $O$ Tempo, 2/09/2011, p. 43).

(21) “[...], isso causaria um cansaço maior ao elenco celeste, [...]" (O Tempo, 2/09/2011, p. 43).

(22) “[...] o momento é o ideal para mudar esse roteiro ruim no Campeonato Brasileiro" $(O$ Tempo, 2/09/2011, p. 42).

(23) “[...], na estreia do time no Campeonato Brasileiro" (O Tempo, 2/09/2011, p. 42).

(24) "Mostrando ter conhecimento do mais tradicional confronto mineiro ele promete buscar inspiração em atacantes como [...]" (Estado de Minas, Super Esportes, 16/08/2011, p. 4).

(25) "Torço para que o nosso meio-campo continue criativo e eficiente [...]" (Estado de Minas, Super Esportes, 16/08/2011, p. 2).

(26) “Cada jogo é uma história, [...]” (Estado de Minas, Super Esportes, 16/08/2011).

O futebol brasileiro é caracterizado pela 'dança' dos seus jogadores que driblam os adversários com manobras que revelam a malandragem da ginga brasileira. A ponto dos jogadores brasileiros terem sido referidos na imprensa alemã durante a Copa do Mundo de 2010 como 'Samba-Jungs', i.e. os meninos do samba (Der Spiegel, 15.06.2010). O conceito de criatividade induzida pelo contexto (KÖVECSES, 2010) pode ajudar a explicar porque numa cultura fortemente marcada pelas artes, como dança e músicas de forte cunho nacional, como a cultura brasileira, metáforas associadas a tais domínios são utilizadas para se falar de outra manifestação da cultura brasileira, que é o futebol.

Outros domínios experienciais utilizados para falar de futebol na imprensa mineira foram JOGO DE AZAR, ALIMENTO, MÁQUINA e NAÇÃO, como veremos nos dados arrolados a seguir.

\subsection{FUTEBOL É JOGO DE AZAR}

Expressões metafóricas motivadas pelo domínio JOGOS DE AZAR (CAMERON, 2010, p. 600) enfatizam a falta de controle da pessoa sobre o desfecho de uma situação.

(27) "Nós não perdemos uma partida na Copa do Mundo e chegamos a um momento em que não temos o controle da situação, que são os pênaltis. Eles são loteria mesmo e não deu para seguir em frente" (Estado de Minas, 11.07.2011). 
O sentido que é atribuído a essa metáfora é de 'estar à mercê de algo' ou ter 'falta de domínio' sobre uma situação. Essa metáfora pode também dar uma idéia de 'manipulação de uma situação'.

Foi tomado como referência aqui o domínio conceitual DOENÇA como proposto por Lakoff e Johnson (1980). Foi encontrada somente uma ocorrência motivada por essa metáfora conceitual nos dados analisados.

(28) “A dispensa e a contratação de jogadores porém, não é a melhor receita [...]" (Estado de Minas, Super Esportes, 16/08/2011, p. 1).

No exemplo (28), 'receita' é uma metonímia para solução. No exemplo a seguir, note-se que uma metáfora do domínio GUERRA aparece associada a uma metáfora do domínio VIDA/ORGANISMO:

(29) “[...] e mesmo uma vitória magra é bem-vinda" (Estado de Minas, Super Esportes, 16/08/2011, p. 5).

A vitória 'magra' seria uma vitória com poucos gols. Tal metaforema (CAMERON e DEIGNAN, 2006) representa um padrão estável de uso contendo julgamentos de valor cultural e temporal específicos. Geralmente, utiliza-se a expressão 'vitoria magra' para se falar sobre futebol ou política, embora o uso não seja restrito somente a esses dois domínios. Na sequência, o domínio VIDA será discutido à luz de alguns exemplos.

\subsection{FUTEBOL É VIDA}

Nos exemplos a seguir, o domínio FUTEBOL é conceitualizado como uma emoção que se experiencia e o técnico é descrito como parte da família, como pai e amigo. Foram encontradas somente cinco (5) ocorrências motivadas por essa metáfora conceitual nos dados analisados.

(30) "O volante Charles volta a viver intensamente o Cruzeiro [...]" (Estado de Minas, Super Esportes, 16/08/2011, p. 5).

(31) "Ele começou a perder o comando quando os dirigentes entenderam que não havia mais espaço no futebol para um técnico mais amigo do que comandante ou mais pai do que treinador" (Estado de Minas, Super Esportes, 03/09/2011, p. 1). 
Nos exemplos acima, foram apresentadas algumas evidências de que o jogador é conceitualizado como uma pessoa que 'vive intensamente' e o técnico é descrito como um 'pai' e 'amigo', o que configura o sub-domínio família dentro do domínio conceitual VIDA.

Agora veja-se um uso metonímico que apareceu na busca sobre futebol.

\subsection{ESTÁDIO/CASA COMO CONTÊINER (LAKOFF, 1987)}

O uso metonímico de CASA para 'estádio de futebol' já havia sido observado na fala dos participantes do grupo focal no estudo sobre metáfora, futebol e violência urbana, quando os participantes do grupo focal relataram sua experiência com violência no futebol (Ferreira, 2013) para referir o 'estádio' como um lugar tão seguro como uma casa, enquanto que a 'rua' é o lugar do perigo, onde acontece a 'batalha', i.e. as brigas de torcidas e com a polícia. Foram encontradas três (3) ocorrências motivadas por essa metonímia conceitual nos dados analisados.

(32) "Fator casa, arma do adversário" (Estado de Minas , Super Esportes, 16/08/2011, p. 5).

(33) "Dentro de casa tem que pensar em vitória [...]" (Estado de Minas, Super Esportes, 16/08/2011, p. 5).

(34) "[...], mas deixou os visitantes dominarem as ações e virar o jogo" (Estado de Minas, Super Esportes, 28/08/2011, p. 6).

Foram apresentadas acima evidências de que a imprensa desportiva conceitualiza metonimicamente o estádio de futebol como uma 'casa' que fornece uma sensação de segurança ao jogador, já que ele teria, supõe-se, o apoio da torcida para conseguir a vitória. O time adversário que vem de fora para jogar na 'casa' é conceitualizado como 'visitante'.

É interessante destacar que o uso metonímico 'casa' também foi verificado na fala dos participantes dos grupos focais tanto em Belo Horizonte como em Fortaleza (FERREIRA et al., 2014), quando esses relataram suas experiências com violência no futebol, ao aludir a 'casa' como o estádio que seria um local policiado e seguro, segundo os torcedores.

Outro domínio experiencial identificado foi MÁQUINA. A seguir serão apresentadas evidências de como o futebol e os jogadores são conceitualizados como máquina e peças da máquina. 


\subsection{FUTEBOL É MÁQUINA}

Esta expressão metafórica sugere que o jogo de futebol é como uma 'máquina com engrenagem' e que o time - e seus jogadores- seriam 'peças dessa engrenagem':

(35) "O problema é que o time não está se encaixando [...]" (Estado de Minas, Super Esportes, 16/08/2011).

Nesse sentido, quando as peças se encaixam, pode-se pressupor que o time funciona e ganha a partida. Se há algum problema com uma peça da engrenagem, no caso com um jogador, o time perde em campo. A partir dessa metáfora, apresentamos as metáforas conceituais que tiveram somente uma (01) ocorrência no corpus estudado no período de tempo delimitado. A seguir serão apresentadas evidências linguísticas de como o futebol é conceitualizado como NAÇÃO e RAÇA.

\subsection{FUTEBOL É NAÇÃO}

A identidade conceitualizada como os domínios NAÇÃO e RAÇA permeia o discurso do esporte em geral, não sendo restrita ao futebol. Quando as seleções nacionais jogam, os torcedores demonstram seu orgulho nacional pendurando bandeiras dos seus países, o mesmo ocorre com relação aos times locais. Ouve-se falar em 'nação corinthiana' e 'raça verdão' (uma referência a outro clube paulista, o Palmeiras), os clubes têm bandeira e hino próprios. Fala-se no 'rei Pelé' e no 'reinado de Maradona' que era considerado o 'rei de Nápoles' na época em que jogou por lá. Tal domínio também motiva expressões nos dados coletados em Minas Gerais:

(36) "O técnico Joel Santana queria um reinado no Cruzeiro" (Estado de Minas, Super Esportes, 16/08/2011, p. 1).

No futebol, os clubes tem 'hino' e 'bandeira' como marca de pertencimento clubístico. Fala-se em um 'time soberano no campeonato', i.e. que está vitorioso. Tratam-se, pois, de marcas de identidade do time em que o clube é conceitualizado como NAÇÃO, os jogadores como 'reis' e os torcedores como 'súditos'. Em alguns campeonatos, como o Campeonato Europeu, a expressão de um sentimento nacional emerge em meio ao futebol, por exemplo na recente vitória da Polônia contra a Alemanha no Estádio Nacional de Varsóvia em 11.10.2014 
nas eliminatórias para o Campeonato Europeu na França em 2016, em que um sentimento nacional de revanche pela destruição causada pelos alemães durante a Segunda Guerra. Tais manifestações de nacionalidade e de rivalidades nacionais são fenômenos observáveis durante campeonatos em que seleções nacionais se enfrentam, momento em que rivalidades e sentimentos nacionais emergem.

\subsection{UM MODELO COGNITIVO IDEALIZADO (MCI) DE FUTEBOL?}

A cognição é corporificada e motivada por situações culturais e cada metáfora reflete um aspecto diferente da compreensão metafórica de alguma experiência (GIBBS, 1994). Lakoff (1987) propõe que cada metáfora conceitual refere um aspecto diferente de um Modelo Cognitivo Idealizado (MCI) e que um modelo cognitivo pode reunir diferentes metáforas contendo vários aspectos de nossa compreensão de uma determinada estrutura conceitual. Tais metáforas podem estar associadas em uma estrutura radial.

No presente trabalho, buscamos apresentar evidências linguísticas e suas respectivas motivações conceituais para corroborar o modelo de Lakoff e Johnson (1980/1999). Os exemplos apresentados, motivados conceitualmente por meio de ações, como o 'duelo' (exemplo 8) ou 'preparar armas' (10), são licenciados por diferentes aspectos de uma gestalt experiencial que vai delinear o domínio GUERRA da metáfora conceitual FUTEBOL É GUERRA, por exemplo. A noção de PARTE/TODO relacionada a um esquema de imagem que reflete a noção de CONTENIMENTO, subjacente à expressão metonímica 'casa' em 'dentro de casa', é outro exemplo de esquema metonímico que vai compor uma estrutura radial a configurar um possível modelo cognitivo idealizado de FUTEBOL. A ideia de CONTENIMENTO também se materializa na língua quando se fala em estar dentro/fora de uma Copa, de uma Liga, de um time e de uma torcida organizada, por exemplo.

Outros ICMs licenciados por metáforas conceituais, utilizados para falar sobre FUTEBOL que apareceram nos dados da mídia examinados no período, foram, além de GUERRA, ARTE, RELIGIÃO, JOGOS DE AZAR, ALIMENTO, VIDA, MÁQUINA, NAÇÃO e MÁGICA. Tais metáforas e metonímias conceituais estão possivelmente associadas em uma estrutura radial que compõe o ICM de futebol situado na cultura brasileira. As evidências linguísticas coletadas em jornais, blogs de torcidas e blogs sobre futebol refletem na mídia 
brasileira a importância que o futebol possui na motivação de expressões metafóricas e metonímicas no Português Brasileiro.

A seguir serão discutidas algumas conclusões do presente estudo.

\section{CONSIDERAÇÕES FINAIS}

Vimos, no presente artigo, como expressões metafóricas e metonímicas são utilizadas na mídia mineira para falar sobre futebol. Apresentamos vários exemplos de expressões metafóricas, cuja motivação conceitual pode corroborar a hipótese de que haja um possível Modelo Cognitivo Idealizado (MCI) de FUTEBOL, estruturado metaforicamente em termos de GUERRA, como ilustrado por expressões como (14) "Confronto direto/As armas de cada um" (Estado de Minas, Super Esportes, 28/08/2011, p. 4), ARTE, como em (22) “[...] o momento é o ideal para mudar esse roteiro ruim no Campeonato Brasileiro" (O Tempo, 2/09/2011, p. 42), assim como cf. os exemplos discutidos anteriormente, que vão utilizar os domínios experiencias VIDA, ALIMENTO, CONTÊINER, RELIGIÃO/MAGIA, JOGO DE AZAR, NAÇÃO e MÁQUINA para falar sobre futebol. Essas metáforas estão, por hipótese, ligadas em uma estrutura radial que vai configurar o MCI de futebol.

O futebol é um componente importante da cultura brasileira e isso naturalmente se reflete no português brasileiro. Os diferentes aspectos do jogo, de seus participantes, assim como elementos da vida cultural que têm relevo na experiência com o futebol, como os ritos simbólicos, são destacados por meio de expressões metafóricas que irão chamar a atenção para alguns aspectos dentro do referido domínio, em detrimento de outros. Tais escolhas certamente estão relacionadas com o papel da cultura e do contexto no uso da língua. Isso pode explicar algumas variações nas escolhas das metáforas na mídia mineira, mais especificamente nos jornais O Tempo e Estado de Minas (Super) no período de 08.07.2011 a 02.09.2011, que foi o objeto do presente estudo, se comparadas com as metáforas utilizadas na mídia portuguesa. $\mathrm{O}$ mesmo foi verificado ao compararmos metáforas e metonímias veiculadas em outros contextos culturais e situacionais, como é o caso de metáforas de futebol usadas pela imprensa alemã.

Ao compararmos evidências de expressões metafóricas de vários domínios experienciais para se falar sobre futebol na imprensa brasileira e na imprensa portuguesa (ALMEIDA e 
SOUSA, 2013), podemos traçar vários paralelos com algumas pequenas diferenças que podem ser atribuídas ao papel desempenhado pela cultura. Tais evidências interlinguísticas revelam uma grande sistematicidade do sistema conceitual humano que se reflete no uso de metáforas e metonímias na língua.

\section{REFERÊNCIAS}

ALMEIDA, M.C.; SOUSA, B. Mesclas e contrafactuais. In ALMEIDA, M.C.; SOUSA, B.; ÓRFÃO, P. ; TEIXEIRA, S. Jogar futebol com as palavras: Imagens metafóricas no Jornal "A Bola". Lisboa: Ed. Colibri, 2013, p. 91-109.

ARANTES, P. C.; FERREIRA, L.C. A metáfora no contexto midiático sociodiscursivo. Anais do IX Encontro do CELSUL. Universidade do Sul de Santa Catarina, Palhoça, 2010. p. 9-21.

ARISTÓTELES. Os Pensadores. São Paulo: Abril, 2000.

CAMERON, L. Responding to the Risk of Terrorism: The Contribution of Metaphor. DELTA [online]. 2010, v. 26, Special issue Metaphor and Cognition, p. 587-614.

CAMERON, L.; DEIGNAN, A. The Emergence of Metaphor in Discourse. Applied Linguistics, 27 (4), p. 671- 690.

DER SPIEGEL. 15.06.2010

DRUMMOND DE ANDRADE, C. Quando é dia de futebol. Rio de Janeiro, Record, 2002.

DURANTI, A. Linguistic Anthropology. New York: CUP, 1997.

ESTADO DE MINAS (SUPER), Belo Horizonte, 11 jul. 2011, p. 1-5.

ESTADO DE MINAS (SUPER), Belo Horizonte, 16 ago. 2011, p. 1-5.

ESTADO DE MINAS (SUPER), Belo Horizonte, 26 ago. 2011, p. 3-4.

ESTADO DE MINAS (SUPER), Belo Horizonte, 28 ago. 2011, p. 2-6.

ESTADO DE MINAS (SUPER), Belo Horizonte, 3 set. 2011, p. 1.

FERREIRA, L. C. Metáfora, Futebol e Violência em Minas Gerais. Revista Signo. vol. 38, n. 65, 2013, p. 273-291.

FERREIRA, L. C. A Conceitualização de violência e futebol. ANTARES, v. 4, n. 7, 2012, p. 166-177.

FERREIRA, L. C. Futebol e metáfora na mídia. IX CONGRESSO LATINO-AMERICANO DE ESTUDOS DO DISCURSO. CD-Rom. FALE, UFMG, Belo Horizonte, 2011.

FERREIRA, L. C. Metáfora e futebol na vida cotidiana. Anais. V Congresso Lingüística e Cognição. Universidade Federal de Santa Catarina. Florianópolis, 2010. Disponível em: 
$<$ http://www.nupffale.ufsc.br/lincognition/Papers/LucianeFERREIRA_95-101.pdf $>$. Acesso em: 17 fev. 2014.

FERREIRA, L. C.; GONÇALVES, B. L. Football and metaphor. IV Congress on Metaphor in Language and Thought. UFRGS, Porto Alegre, 2011. Comunicação oral.

FERREIRA, L. C.; SILVA, P. H. S. O discurso sobre futebol e violência em Minas Gerais. Revista Scripta, Vol. 18, nr. 34, 2014.

FOLHA DE SÃO PAULO, São Paulo, 20 out 2010.

FRANCO Jr., H. A Dança dos Deuses: Futebol, Sociedade, Cultura. São Paulo: Companhia das Letras, 2007.

GIBBS, R. Embodiment and Cognitive Science. Cambridge; New York: Cambridge University Press, 2006.

GIBBS, R. The Poetics of Mind. New York: CUP, 1994.

GIBBS Jr., R.W. Taking metaphor out of our heads and putting it into the cultural world. In: GIBBS, R. W.; STEEN, G. (Ed.). Metaphor in cognitive linguistics. Amsterdam: John Benjamins, 1999. p. 146-166.

GIBBS, R.; FERREIRA, L.C. Do people infer the entailments of conceptual metaphors during verbal metaphor understanding? In $\mathrm{M}$. Brdar \& M. Fuchs (Ed.). Converging and diverging tendencies in cognitive linguistics. Amsterdam : John Benjamins, 2011.

GRADY, J. Foundations of Meaning: Primary Metaphors and Primary Scenes. Ph.D. thesis, UC Berkeley, 1997.

HASER, V. Metaphor, Metonymy, and Experientialist Philosophy: Challenging Cognitive Semantics. Berlin: Mouton de Gruyter, 2005.

KÖVECSES, Z. Metaphor: a Practical Introduction. $2^{\text {nd }}$ ed. New York: Oxford University Press, 2010.

KÖVECSES, Z. Metaphor in Culture. Universality and Variation. Cambridge: CUP, 2005.

LAKOFF, G. Women, Fire, and Dangerous Things: What Categories Reveal About the Mind. Chicago: Chicago University Press, 1987.

LAKOFF, G.; JOHNSON, M. Metaphors we live by. London: University of Chicago Press, 1980.

MACHADO, I. 8 anos de Lula em uma partida de futebol. UOL notícias. Dez/2010. Disponível em: $<$ http://noticias.uol.com.br/politica/ultimas-noticias/2011/01/03/8-anos-de-lula-emuma-partida-de-futebol.htm > Acesso em: 17 fev 2014.

MAHON, J. Getting your Sources Right: What Aristotle did't Say. Researching and Applying Metaphor. CAMERON, L.; LOW,G. (Eds.) Cambridge: CUP, 1999. p. 69-80.

O TEMPO, Belo Horizonte, 2011, p. 5. 
O TEMPO, Belo Horizonte, 2 set 2011, p. 38, 41, 43.

PORTO, M. D.; ROMANO. M. Newspaper Metaphors: Reusing Metaphors Across Media Genres, Metaphor and Symbol, 28:1, 2013. p. 60-7 acesso em http://dx.doi.org/10.1080/10926488.2013.744572

SIMÓ, J. Chess Metaphors in American English and Hungarian. Metaphor and Symbol. Vol. $24, n^{\circ} 1,2008$.

REDDY, M. J. The Conduit Metaphor: A Case of Frame Conflict in our Language about Language. In: Ortony, A. (Org.). Metaphor and Thought. 1979.

SEMINO, E; MASCHI, M. Politics is football: Metaphor in the Discourse of Silvio Berlusconi in Italy. In: Discourse and Society. 1996. p. 243-269.

SEMINO, E; HEYWOOD, J; SHORT, M. Methodological Problems in the Analysis of Metaphors in a Corpus of Conversations about Cancer. Journal of Pragmatics, 36, 2004, p. 12711294.

THE SUN, 19.6.2004

WISNIK, J.M. Veneno Remédio. O futebol e o Brasil. São Paulo: Companhia das Letras, 2007.

Recebido em 14 de março de 2015.

Aceito em 10 de maio de 2015. 